\title{
Quality of Life after Intestinal Resection in Patients with Crohn Disease: A Systematic Review
}

\author{
Francis J. Ha ${ }^{a}$ Louisa Thong ${ }^{a}$ Hanan Khalil ${ }^{a, b}$ \\ ${ }^{a}$ Faculty of Medicine, Nursing and Health Sciences, and ${ }^{b}$ Centre for Chronic Diseases Management, Monash Rural \\ Health, Joanna Briggs Centre, Monash University, Moe, VIC, Australia
}

\section{Keywords}

Crohn disease $\cdot$ Surgery $\cdot$ Intestinal resection - Quality of life

\section{Abstract}

Background/Aims: Most patients with Crohn disease (CD) require surgery within 10 years of diagnosis. Intestinal resection is the most commonly performed operation although the effects on health-related quality of life (HRQOL), particularly long-term, are contentious. Methods: We conducted a systematic review evaluating the impact of intestinal resection on the HRQOL of CD patients, predictors of postoperative HRQOL, and patient satisfaction with surgery. Results: Nine studies including 1,108 CD patients undergoing intestinal resection were identified as eligible for inclusion. The median age at surgery was 29-41 years with varying followup period (range 30 days -5 years). Ileocolic resection was the most commonly performed operation on an elective basis (range 95-100\%). HRQOL improved as early as 2 weeks postoperatively and lasted up to 5 years across both generic and gastrointestinal domains. Gender, smoking, and disease recurrence were potential predictors of postoperative HRQOL. Patient satisfaction is high with regard to surgery, with preference for a laparoscopic approach. Conclusion: Intestinal resection in $C D$ patients improved $H R Q O L$ in the

\section{KARGER}

(C) 2017 S. Karger AG, Basel

E-Mail karger@karger.com

www.karger.com/dsu short- and long-term and patients describe high satisfaction about their surgery. Further studies are needed to validate potential predictors of postoperative HRQOL in this cohort.

(c) 2017 S. Karger AG, Basel

\section{Introduction}

Crohn disease (CD) is a chronic, relapsing inflammatory bowel disease (IBD) associated with significant morbidity. Most patients require surgical intervention within 10 years of diagnosis, and multiple intestinal surgeries may be needed throughout their lifetime [1-3]. Surgery for CD can vary; choice of procedure depends on disease location, treatment urgency, frequency of recurrence, and patient preference [4]. Intestinal resection, usually in the form of an ileocecal resection, is the most commonly performed operation for CD [5]. Indications for intestinal resection include stricturing disease, obstruction, and failure of medical therapy. Irrespective of the surgical treatments available, many $\mathrm{CD}$ patients experience significant disruption to their activities of daily living and quality oflife (QOL) [6-8]. Health-related QOL (HRQOL) is considered not only the absence of disease or infirmity, but also the interaction between one's physical health,

Dr. Hanan Khalil, PhD

Senior Lecturer, Department of Rural Health

Faculty of Medicine, Nursing and Health Science, Monash University

Ollerton Rd., Moe, VIC 3825 (Australia)

E-Mail hanan.khalil@monash.edu 
psychological state, and environment $[9,10]$. It is recognized as an accurate reflection of $\mathrm{CD}$ activity, and thus therapeutic efficacy [11]. As such, a well-established goal of surgery is to achieve and maintain improved patient health status [12]. The effect of surgery on the HRQOL of $\mathrm{CD}$ patients is contentious, particularly with potential postoperative complications, disease recurrence in the long term, and in the era of biologic agents. No review has systematically evaluated the HRQOL of CD patients following intestinal resection.

\section{Objectives}

We conducted a systematic review to evaluate the effect of intestinal resection on the HRQOL of CD patients, their satisfaction toward surgery, and any predictors of HRQOL after surgery.

\section{Methods}

The protocol for this systematic review was registered with the PROSPERO International prospective register of systematic reviews prior to data extraction in accordance with their quality standards (registration No. CRD42016044171). This systematic review is structured with consideration for previously published guidelines and in accordance with the PRISMA statement for conducting systematic reviews (online suppl. Table 1; for all online suppl. material, see www.karger.com/doi/10.1159/000453590) $[13,14]$.

\section{Search Strategy}

A systematic search of OVID MEDLINE was conducted using $\mathrm{MeSH}$ terms "Crohn disease" AND "quality of life," limited to studies in English Language and published from 1995 onward. We performed a further search of Embase and Cochrane databases as well as the bibliographies of included articles to identify additional references.

\section{Eligibility Criteria}

We included prospectively designed and retrospective observational studies in patients diagnosed with $\mathrm{CD}$, who had undergone intestinal resection. We excluded studies that did not evaluate HRQOL at baseline prior to surgery.

\section{Study Selection and Data Extraction}

Titles and abstracts identified through the searches were screened for relevance by 2 reviewers. Data were extracted using standardized pre-specified forms and included overall patient demographics, pre-operative medications, and follow-up period. With regard to surgery, data were collected on type of intestinal resection, indication for surgery, and need (elective, emergent, or urgent) of surgery. In relation to HRQOL, we collected data on HRQOL before and after surgery, patient satisfaction, and any reported predictors or factors associated with postoperative HRQOL. We assessed the risk of bias according to the US Preventive Ser-

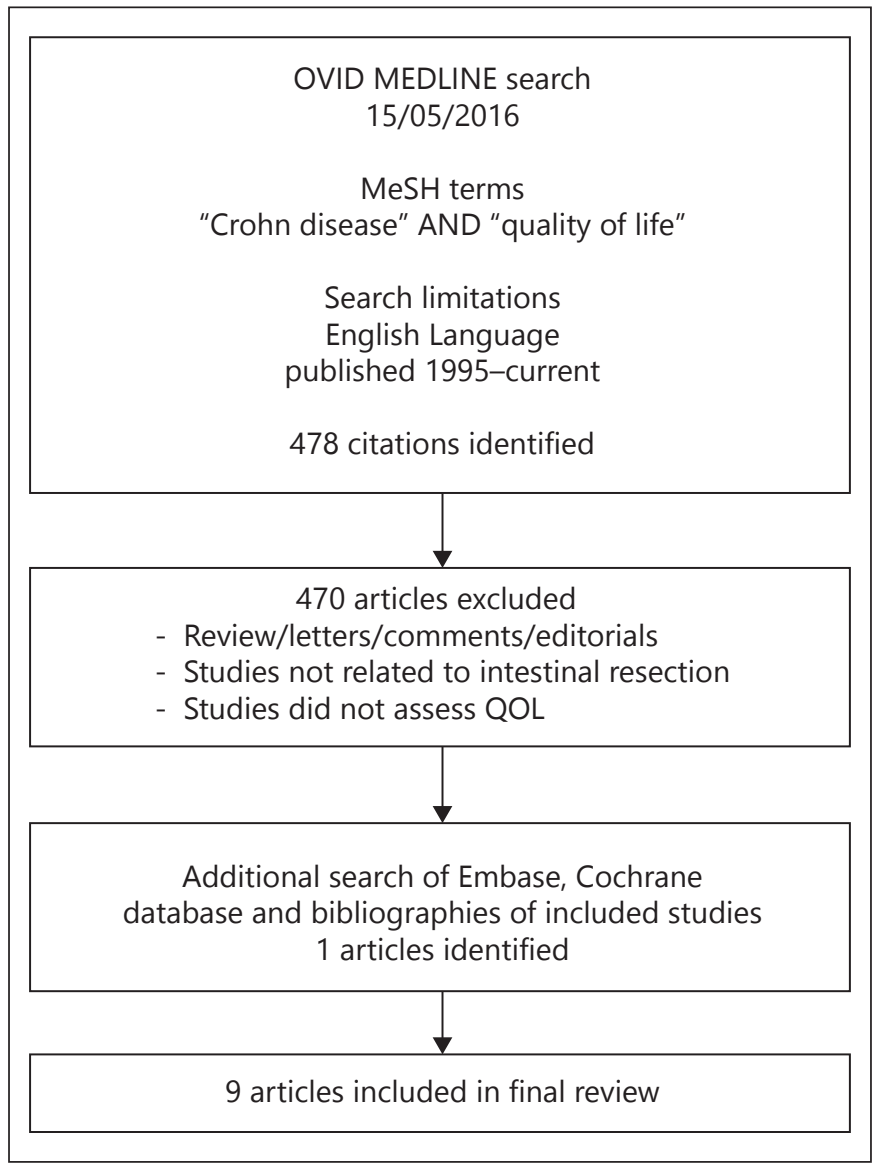

Fig. 1. Search algorithm. QOL, quality of life.

vices Task Force Quality Rating Criteria (online suppl. Table 2) [15]. Quality of included studies was further evaluated by study design, follow-up methodology, and consistency of follow-up.

\section{Short-Term versus Long-Term HRQOL}

The distinction between short- and long-term HRQOL in patients with $\mathrm{CD}$ is important given the immediate postoperative impact of surgery on functional status, the risk of disease recurrence, and the young age of affected patients. For the purposes of this study, a follow-up of up to 1 year was considered short term. This was deemed appropriate as most patients had recovered functionally from any minor postoperative complications, therefore, enabling adequate time for early disease recurrence which can occur in up to one-third of patients within the first year post surgery [16].

\section{Results}

Nine studies were eligible for the final review (Fig. 1) [17-25]. Two studies $[21,22]$ originated from the same tertiary center during the same recruitment period with the only difference being the duration of follow-up. Thus, 
only the study with longer follow-up was included in the tabulated synthesis [22]. In one study, the prescribed medications were reported in a separate study on the same cohort of patients, and thus, relevant data were obtained from this study [26].

\section{HRQOL Instruments}

HRQOL instruments used in the included studies were either generic or gastrointestinal-specific measures. Three studies used the Short-Form 36 (SF-36) item questionnaire [27], and 1 study used a modified version of the SF-36, the Health Status Questionnaire [22]. Two studies used the generic Cleveland Global Quality of Life questionnaire [17, 18, 28], and further separate studies used the Treatment Satisfaction Questionnaire $[20,29]$, Time Trade-Off Technique instrument $[23,30]$, and Direct Questioning of Objectives instrument [23]. Gastrointestinal-specific HRQOL instruments included the Gastrointestinal Quality of Life Instrument (GIQLI) $[19,31]$ and the Inflammatory Bowel Disease Questionnaire (IBDQ) [24, 32] each used in 1 study, and the Rating Form of Inflammatory Bowel Disease Patient Concerns instrument used in 2 studies $[23,25,33]$. Details of the components and scoring system of each HRQOL instrument are summarized in Table 1.

\section{Characteristics of Included Studies}

In 9 studies, a total of 1,108 patients with CD underwent intestinal resection. Two studies were randomized trials [19,24], 3 further studies involved a single arm of prospectively enrolled patients undergoing intestinal resection $[20,23,25]$, and 4 studies were retrospective observational studies derived from prospectively maintained databases [17, 18, 21, 22]. Studies were published from 1997 to 2015 and recruitment period ranged from 1994 to 2011. Four studies were conducted across Europe $[19,20,23,25], 3$ were conducted in the United States [17, 18, 22], and 1 conducted in Australia [24]. The follow-up period varied from as early as 30 days to 5 years after surgery with follow-up being through outpatient clinic, telephone contact, or retrospective hospital record review from a prospectively maintained database. Two studies did not specify the method of follow-up [19, 22]. Consistency of follow-up was also varied; 3 studies had no patients lost on follow-up [20,23,25] while another 3 studies had more than $30 \%$ of patients who withdrew early or were lost on follow-up [17, 22, 24]. One study did not report maintenance of follow-up [19]. Further details of included studies characteristics are described in Table 2.

QOL after Intestinal Resection in Patients with CD

\section{Patient Demographics}

There were about equal proportions of men and women across the studies (range 43-63\% for men) and median age at the time of surgery ranged from 29 to 41 years. Duration of disease was reported in 4 studies, ranging from 2 to 9.3 years (online suppl. Table 3). Pre-operative medications were reported in 5 studies and included corticosteroids (range 26-67\%), any thiopurine (range 21$83 \%$ ), 5-ASA (range $23-57 \%$ ), and methotrexate or other unspecified immunomodulators (range 18-30\%; online suppl. Table 4). The use of specified biologic agents was only reported in the most recent included study with about one-quarters of patients (24\%) [24].

\section{Characteristics of Surgery}

Ileocolic resection was the most commonly performed intestinal resection (range 57-100\%; online suppl. Table 5). Colectomy (segmental, subtotal, or total) operations were also performed in up to $31 \%$ of cases and additional operations included ileal pouch anal anastomosis, strictureplasty, and perianal surgery $[17,18,20]$. The vast majority of intestinal resections were performed electively (range 95-100\%) and indications for surgery were most commonly bowel obstruction (range 23-79\%), stricturing disease (24\%), perforation ( $40-53 \%)$, and failure of medical therapy (4-29\%).

\section{Effect of Intestinal Resection on HRQOL}

HRQOL was evaluated at pre-operative baseline and during the postoperative follow-up period for all included studies. For short-term HRQOL, all studies reported a significant improvement after intestinal resection and this was found as early as 30 days postoperatively [17]. One study evaluated HRQOL 1 week after intestinal resection and reported a significant decline on SF-36 and total GIQLI score [19]. However, by 2 weeks after surgery, patients had returned to their pre-operative baseline HRQOL, and by 4 weeks, significant improvements across all measures compared to baseline were reported. Five studies evaluated long-term HRQOL after intestinal resection, and all but one study found significant improvement in HRQOL lasting up to 5 years $[18,20,22-$ $24]$. In the single prospective study that failed to find significant improvement 2 years after surgery, this included patients with chronic inflammatory activity at follow-up (measured by the CD activity index) [23]. When these patients were excluded from analyses, patient without chronic inflammatory activity described significant improvement across all HRQOL scales [23]. In contrast, a retrospective study found that patients with longer fol- 


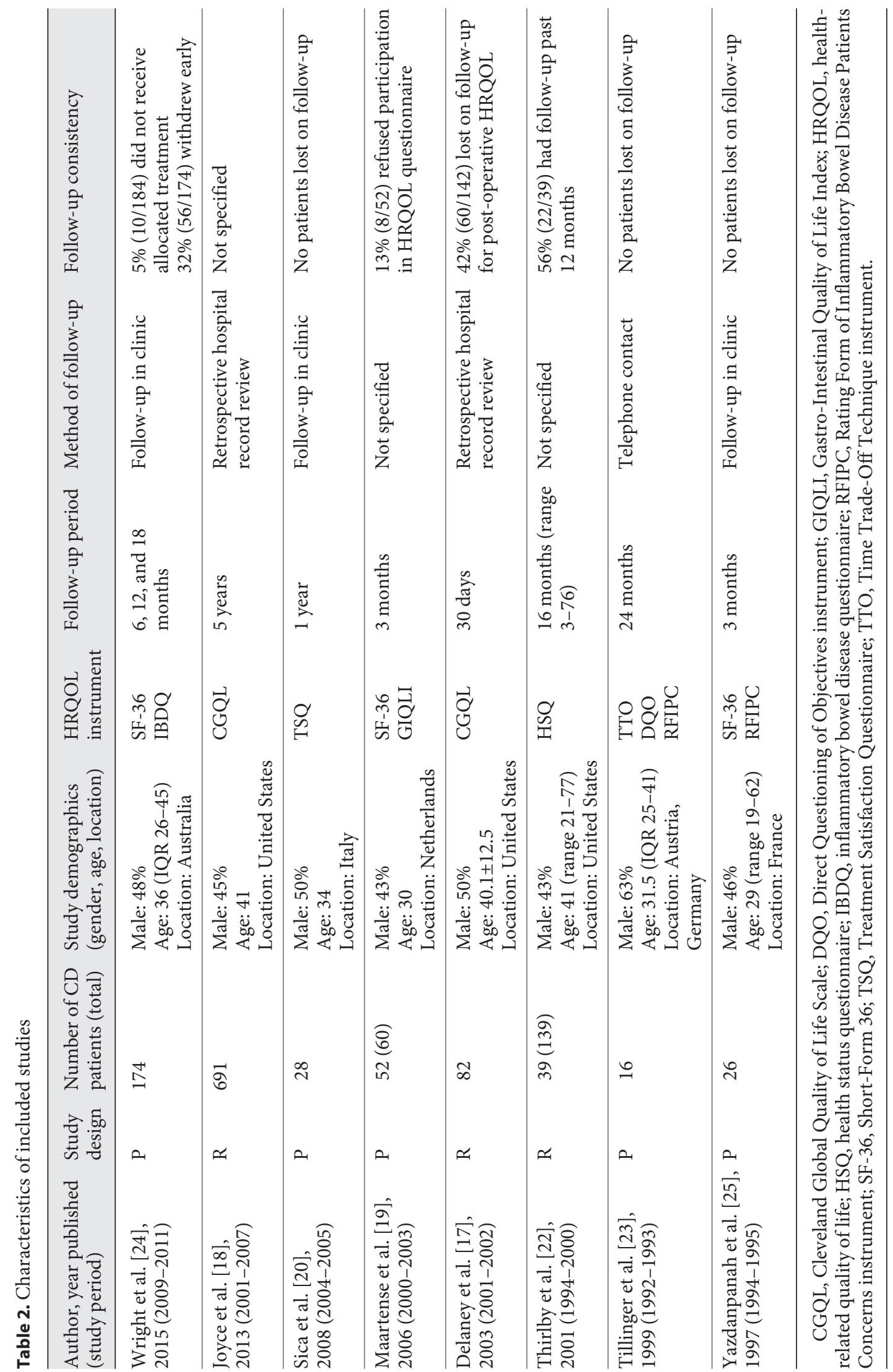


smoking status [18, 24]. In 3 studies that evaluated the effect of open approach compared to laparoscopic approach to intestinal resection, none found any significant difference in HRQOL up to 18 months of follow-up [19, 20,24]. There are inconsistencies with regards to the impact of postoperative complications and disease recurrence being associated with limited improvement in HRQOL. Two earlier prospective studies found that both were significant determinants of postoperative HRQOL, while the most recent study that was included failed to find significant associations with either factor [17, 23, 24]. Receiving a biologic therapy (adalimumab) was also not associated with any greater improvement in HRQOL after surgery in this randomized trial [24].

\section{Patient Satisfaction towards Surgery}

Only 2 studies evaluated the patient satisfaction and their views toward surgery postoperatively $[17,20]$. Up to $80 \%$ of assessable patients were satisfied with their intestinal resection and would undergo it again, if necessary [17]. Of note, the majority (64\%) of these patients had undergone an open approach. Conversely, another study of ileocolic resection found that $80 \%$ of patients who underwent an open approach and about $92 \%$ of patients who underwent a laparoscopic approach would prefer a laparoscopic approach if they had to undergo the surgery again [20].

\section{Discussion}

\section{Strength of Evidence and Assessment of Bias}

The strength of evidence was systematically assessed in this review. Across the 9 studies (including 2 studies originating from the same centre), 9 different HRQOL instruments were used across both generic and gastrointestinalspecific domains which precluded performing any metaanalysis. Four studies involved prospectively enrolled patients and 5 studies were retrospective, although they were derived from prospectively maintained databases. Follow-up consistency ranged from 56 to $100 \%$ at specified time points, and the methods of follow-up also varied, although most were conducted through assessment in outpatient clinic. Overall, the quality of included studies ranged from "fair" to "good" according to the US Preventive Services Task Force Quality Rating Criteria [15].

\section{Summary of Main Findings and Interpretation}

This is the first systematic review to evaluate HRQOL, relevant predictors after intestinal resection, and satisfaction toward surgery in $\mathrm{CD}$ patients. The main findings of this systematic review are that patients with CD report (1) significant improvement in HRQOL as early as 30 days and up to 5 years after intestinal resection [17-20, 22-25], (2) initial functional decline up to 2 weeks postoperatively [19], and (3) high satisfaction toward their surgery with preference for a laparoscopic approach $[17,20]$. Lastly, gender, smoking, and disease recurrence were identified as potential predictors of HRQOL improvement after intestinal resection $[17,18,24]$.

Arguably, HRQOL is the primary outcome for patients with CD given the relatively young age of affected patients and the chronic disease course [34]. It is well known that CD patients experience significant impairment in their HRQOL compared to the general population, particularly with pediatric onset [35-37]. Surgery, specifically intestinal resection, is usually reserved for medical therapy failure or for mechanical problems such as obstruction, stricturing disease, or perforation [38]. Yet the effect of surgery on HRQOL may be altered due to the evolved treatment landscape for CD patients over the last 2 decades, including established use of anti-tumor necrosis factor agents and uptake of laparoscopic surgery [39].

The consistent finding that HRQOL improves after intestinal resection across all included studies is reassuring for clinicians and patients. This marked improvement across the recruitment period ranging from 1994 to 2011 highlights that surgery remains an established aspect of management despite increasing and possibly earlier use of biologic agents following initial diagnosis of CD [40]. Included studies were conducted across Europe, the United States of America, and Australia; and thus, the findings are generalizable to cohorts worldwide. The variety of adopted HRQOL instruments and their respective positive findings further demonstrate that intestinal resection is likely effective in improving broader facets of HRQOL including generic and gastrointestinal-specific aspects.

Predictors of HRQOL after surgery for CD patients are less clear. Women reporting lower HRQOL at pre-operative baseline and in the short-term postoperative period are consistent with studies evaluating predictors of HRQOL in CD patients in general $[8,41,42]$. However, the similar HRQOL reported by men and women by 18 months after surgery may suggest that postoperative HRQOL is better explained by other factors such as smoking or disease recurrence. Smoking is a well-established risk factor for $\mathrm{CD}$ and increases the risk of flares of disease activity and flares after surgery $[24,43,44]$. However, this risk is reduced upon smoking cessation and a smoking
360

Dig Surg 2017;34:355-363

DOI: $10.1159 / 000453590$
Ha/Thong/Khalil 
intervention programme involving counseling, and nicotine replacement therapy up to 8 weeks prior to surgery significantly reduces the risk of postoperative complications compared to those who continue to smoke $[44,45]$. While disease recurrence and activity as a predictor of postoperative HRQOL showed mixed results in the included studies, this may be due to the limited number of studies and thus pooled cohort size [23,24]. It has otherwise been associated with poorer HRQOL in CD patients $[46,47]$ including post surgery $[8,37]$, and the aim to improve HRQOL should focus on inducing remission regardless of a medical or surgical approach. It is uncertain whether disease duration prior to first surgery affects postoperative HRQOL. Although such patients would appear to have a more aggressive disease course mandating earlier surgery, Wright et al. [24] found no association with duration of disease of less than 10 years and HRQOL. This might suggest that surgery is effective in improving HRQOL regardless of prior disease course although this would depend on the extent of resection, need for a permanent ileostomy, and residual perianal disease including incontinence, which are factors impacting patient health status $[48,49]$.

There was no difference in the HRQOL of CD patients who underwent intestinal resection through a laparoscopic approach compared to open surgery [19, $20,24]$. Although a laparoscopic approach usually requires a longer operating time and also risks requiring conversion to an open approach [50], it is associated with comparable or reduced perioperative complications and fewer incisional hernias [51, 52]. Furthermore, patients undergoing laparoscopic surgery describe better cosmesis and most patients prefer a laparoscopic approach if second surgery is required $[20,36]$. Nevertheless, patient satisfaction with the outcome of surgery is high, and patients should be offered either approach particularly when performed on an elective basis with consideration of the potentially increased cost associated with a laparoscopic approach and surgeon experience [17].

\section{Review Limitations}

We acknowledge that the level of evidence of this systematic review is limited by the level of evidence of the included studies. We aimed to reduce assessment bias by appraising studies according to the US Preventive Services Task Force Quality Rating Criteria and by evaluating follow-up consistency. We did not exclude studies that used non-validated HRQOL instruments for the purposes of this study due to the lack of studies overall in the

QOL after Intestinal Resection in Patients with CD literature. Inconsistent reporting of data items including disease duration, pre-operative medications, and indications for surgery also limits interpretation with regards to predictors of HRQOL after surgery. The exclusion of studies published prior to 1995 reduces inclusion of CD patient cohorts that were treated with a different clinical approach, particularly with regards to medical therapy. Finally, our inclusion of only the studies that reported both pre-operative baseline and postoperative HRQOL enabled definitive interpretation as to the distinct role of intestinal resection in $\mathrm{CD}$ patients.

\section{Implications for Future Research}

This review demonstrates that while intestinal resection is associated with improved HRQOL both in the short and long term, the timing of surgery and certain factors influencing postoperative HRQOL remain uncertain. The heterogeneity of HRQOL instruments can obscure interpretation, and the use of established, validated instruments is warranted to enable definitive conclusions. The evaluation of HRQOL prior to and after surgery would also allow clear understanding of how surgery impacts HRQOL without problematic confounding factors such as disease activity, cigarette smoking, and different medical therapy. Lastly, the role of intestinal resection amidst the growing trend toward early introduction of biologic agents in patients at high risk of disabling disease is less clear [53]. Findings from the LIR!C trial may help elucidate the appropriate timing of surgery [54].

\section{Conclusion}

Intestinal resection for $\mathrm{CD}$ patients improves HRQOL across both generic and gastrointestinal-specific domains in the short and long term. Gender, smoking influence post-operative HRQOL, and disease recurrence are also likely factors. Patients describe high satisfaction toward their surgery although patients tend to prefer a laparoscopic approach compared to open surgery.

\section{Disclosure Statement}

The authors declare no conflicts of interest.

\section{Funding}

No funding was received by any authors. 


\section{References}

1 Bernell O, Lapidus A, Hellers G: Risk factors for surgery and postoperative recurrence in Crohn's disease. Ann Surg 2000;231:38-45.

2 Broering DC, Eisenberger CF, Koch A, et al: Strictureplasty for large bowel stenosis in Crohn's disease: quality of life after surgical therapy. Int J Colorectal Dis 2001;16:8187.

3 Broering DC, Eisenberger CF, Koch A, et al: Quality of life after surgical therapy of small bowel stenosis in Crohn's disease. Dig Surg 2001;18:124-130.

4 Seifarth C, Kreis ME, Grone J: Indications and specific surgical techniques in Crohn's disease. Viszeralmedizin 2015;31:273-279.

5 Jones DW, Finlayson SR: Trends in surgery for Crohn's disease in the era of infliximab. Ann Surg 2010;252:307-312.

6 Devlen J, Beusterien K, Yen L, et al: The burden of inflammatory bowel disease: a patientreported qualitative analysis and development of a conceptual model. Inflamm Bowel Dis 2014;20:545-552.

7 van der Have M, van der Aalst KS, Kaptein AA, et al: Determinants of health-related quality of life in Crohn's disease: a systematic review and meta-analysis. J Crohns Colitis 2014;8:93-106

8 Casellas F, Lopez-Vivancos J, Badia X, et al: Impact of surgery for Crohn's disease on health-related quality of life. Am J Gastroenterol 2000;95:177-182.

9 Testa MA, Simonson DC: Assessment of quality-of-life outcomes. N Engl J Med 1996; 334:835-840

10 Study protocol for the World Health Organization project to develop a Quality of Life assessment instrument (WHOQOL). Qual Life Res 1993;2:153-159.

11 Irvine EJ, Feagan B, Rochon J, et al: Quality of life: a valid and reliable measure of therapeutic efficacy in the treatment of inflammatory bowel disease. Canadian Crohn's Relapse Prevention Trial Study Group. Gastroenterology 1994;106:287-296.

12 Meyers S, Walfish JS, Sachar DB, et al: Quality of life after surgery for Crohn's disease: a psychosocial survey. Gastroenterology 1980; 78:1-6.

13 Moher D, Liberati A, Tetzlaff J, et al: Preferred reporting items for systematic reviews and meta-analyses: the PRISMA statement. Int J Surg 2010;8:336-341.

14 Wille-Jørgensen P, Renehan AG: Systematic reviews and meta-analyses in coloproctology: interpretation and potential pitfalls. Colorectal Dis 2008;10:21-32.

15 Chou R, Dana T: Update of the 2004 Evidence Review for the US Preventive Services Task Force. Rockville, 2010. http://www.ncbi.nlm. nih.gov/books/NBK47515/ (accessed May 25, 2016).

16 Rutgeerts P: Protagonist: Crohn's disease recurrence can be prevented after ileal resection. Gut 2002;51:152-153.
17 Delaney CP, Kiran RP, Senagore AJ, et al: Quality of life improves within 30 days of surgery for Crohn's disease. J Am Coll Surg 2003; 196:714-721.

18 Joyce MR, Hannaway CD, Strong SA, et al: Impact of smoking on disease phenotype and postoperative outcomes for Crohn's disease patients undergoing surgery. Langenbecks Arch Surg 2013;398:39-45.

19 Maartense S, Dunker MS, Slors JF, et al: Laparoscopic-assisted versus open ileocolic resection for Crohn's disease: a randomized trial. Ann Surg 2006;243:143-149; discussion 150-153.

20 Sica GS, Iaculli E, Benavoli D, et al: Laparoscopic versus open ileo-colonic resection in Crohn's disease: short- and long-term results from a prospective longitudinal study. J Gastrointest Surg 2008;12:1094-1102.

21 Thirlby RC, Land JC, Fenster LF, et al: Effect of surgery on health-related quality of life in patients with inflammatory bowel disease: a prospective study. Arch Surg 1998;133:826832.

22 Thirlby RC, Sobrino MA, Randall JB: The long-term benefit of surgery on health-related quality of life in patients with inflammatory bowel disease. Arch Surg 2001;136:521527.

23 Tillinger W, Mittermaier C, Lochs $\mathrm{H}$, et al: Health-related quality of life in patients with Crohn's disease: influence of surgical operation - a prospective trial. Dig Dis Sci 1999;44: 932-938.

24 Wright EK, Kamm MA, De Cruz P, et al: Effect of intestinal resection on quality of life in Crohn's disease. J Crohns Colitis 2015;9:452462.

25 Yazdanpanah Y, Klein O, Gambiez L, et al: Impact of surgery on quality of life in Crohn's disease. Am J Gastroenterol 1997;92:18971900.

26 De Cruz P, Kamm MA, Hamilton AL, et al: Crohn's disease management after intestinal resection: a randomised trial. Lancet 2015; 385:1406-1417.

27 Ware JE Jr, Sherbourne CD: The MOS 36item short-form health survey (SF-36). I. Conceptual framework and item selection. Med Care 1992:30:473-483.

28 Kiran RP, Delaney CP, Senagore AJ, et al: Prospective assessment of Cleveland Global Quality of Life (CGQL) as a novel marker of quality of life and disease activity in Crohn's disease. Am J Gastroenterol 2003;98:17831789.

29 Dunker MS, Stiggelbout AM, van Hogezand RA, et al: Cosmesis and body image after laparoscopic-assisted and open ileocolic resection for Crohn's disease. Surg Endosc 1998; 12:1334-1340.

30 Mohide EA, Torrance GW, Streiner DL, et al: Measuring the wellbeing of family caregivers using the time trade-off technique. J Clin Epidemiol 1988;41:475-482.
31 Eypasch E, Williams JI, Wood-Dauphinee S, et al: Gastrointestinal Quality of Life Index: development, validation and application of a new instrument. Br J Surg 1995;82:216222.

32 Guyatt G, Mitchell A, Irvine EJ, et al: A new measure of health status for clinical trials in inflammatory bowel disease. Gastroenterology 1989;96:804-810.

33 Drossman DA, Leserman J, Li ZM, et al: The rating form of IBD patient concerns: a new measure of health status. Psychosom Med 1991;53:701-712.

34 Ha F, Khalil H: Crohn's disease: a clinical update. Therap Adv Gastroenterol 2015;8:352359.

35 Turunen $\mathrm{P}$, Ashorn M, Auvinen A, et al: Long-term health outcomes in pediatric inflammatory bowel disease: a populationbased study. Inflamm Bowel Dis 2009;15:5662.

36 Eshuis EJ, Polle SW, Slors JF, et al: Long-term surgical recurrence, morbidity, quality of life, and body image of laparoscopic-assisted vs. open ileocolic resection for Crohn's disease: a comparative study. Dis Colon Rectum 2008; 51:858-867.

37 Scarpa M, Ruffolo C, D'Inca R, et al: Healthrelated quality of life after ileocolonic resection for Crohn's disease: long-term results. Inflamm Bowel Dis 2007;13:462-469.

38 Poggioli G, Pierangeli F, Laureti S, et al: Review article: indication and type of surgery in Crohn's disease. Aliment Pharmacol Ther 2002;16(suppl 4):59-64.

39 Cosnes J, Bourrier A, Nion-Larmurier I, et al: Factors affecting outcomes in Crohn's disease over 15 years. Gut 2012;61:1140-1145.

40 Khanna R, Bressler B, Levesque BG, et al: Early combined immunosuppression for the management of Crohn's disease (REACT): a cluster randomised controlled trial. Lancet 2015;386:1825-1834.

41 Tabibian A, Tabibian JH, Beckman LJ, et al: Predictors of health-related quality of life and adherence in Crohn's disease and ulcerative colitis: implications for clinical management. Dig Dis Sci 2015;60:1366-1374.

42 Moradkhani A, Beckman LJ, Tabibian JH: Health-related quality of life in inflammatory bowel disease: psychosocial, clinical, socioeconomic, and demographic predictors. J Crohns Colitis 2013;7:467-473.

43 Mahid SS, Minor KS, Soto RE, et al: Smoking and inflammatory bowel disease: a meta-analysis. Mayo Clin Proc 2006;81:1462-1471.

44 To N, Gracie DJ, Ford AC: Systematic review with meta-analysis: the adverse effects of tobacco smoking on the natural history of Crohn's disease. Aliment Pharmacol Ther 2016;43:549-561.

45 Moller AM, Villebro N, Pedersen T, et al: Effect of preoperative smoking intervention on postoperative complications: a randomised clinical trial. Lancet 2002;359:114-117. 
46 Kalafateli M, Triantos C, Theocharis G, et al: Health-related quality of life in patients with inflammatory bowel disease: a single-center experience. Ann Gastroenterol 2013;26:243248.

47 Bernklev T, Jahnsen J, Schulz T, et al: Course of disease, drug treatment and health-related quality of life in patients with inflammatory bowel disease 5 years after initial diagnosis. Eur J Gastroenterol Hepatol 2005;17:1037-1045.

48 Andersson P, Olaison G, Bendtsen P, et al: Health related quality of life in Crohn's proctocolitis does not differ from a general population when in remission. Colorectal Dis 2003;5:56-62.
49 Mueller MH, Geis M, Glatzle J, et al: Risk of fecal diversion in complicated perianal Crohn's disease. J Gastrointest Surg 2007;11: 529-537.

50 Basse L, Jakobsen DH, Bardram L, et al: Functional recovery after open versus laparoscopic colonic resection: a randomized, blinded study. Ann Surg 2005;241:416-423.

51 Patel SV, Patel SV, Ramagopalan SV, et al: Laparoscopic surgery for Crohn's disease: a meta-analysis of perioperative complications and long term outcomes compared with open surgery. BMC Surg 2013;13:14.
52 Kristo I, Stift A, Argeny S, et al: Minimalinvasive approach for penetrating Crohn's disease is not associated with increased complications. Surg Endosc 2016;30:52395244.

53 Danese S, Colombel JF, Reinisch W, et al: Review article: infliximab for Crohn's disease treatment - shifting therapeutic strategies after 10 years of clinical experience. Aliment Pharmacol Ther 2011;33:857-869.

54 Eshuis EJ, Bemelman WA, van Bodegraven AA, et al: Laparoscopic ileocolic resection versus infliximab treatment of distal ileitis in Crohn's disease: a randomized multicenter trial (LIR!C-trial). BMC Surg 2008;8:15. 